\title{
Deep sedation for endoscopic retrograde cholangiopancreatography: a comparison between clinical assessment and Narcotrend ${ }^{\mathrm{TM}}$ monitoring
}

This article was published in the following Dove Press journal:

Medical Devices: Evidence and Research

15 March 20II

Number of times this article has been viewed

\section{Somchai Amornyotin \\ Wiyada Chalayonnawin \\ Siriporn Kongphlay}

Department of Anesthesiology and Siriraj GI Endoscopy Center, Faculty of Medicine, Siriraj Hospital, Mahidol University, Bangkok, Thailand
Correspondence: Somchai Amornyotin Department of Anesthesiology, Faculty of Medicine, Siriraj Hospital, Mahidol University, Bangkok, 10700, Thailand Tel +6624197990

Fax+662 4II 3256

Email sisam@mahidol.ac.th
Introduction: Moderate to deep sedation is generally used for endoscopic retrograde cholangiopancreatography (ERCP). The depth of sedation is usually judged by clinical assessment and electroencephalography-guided monitoring. The aim of this study was to compare the clinical efficacy of clinical assessment and Narcotrend ${ }^{\mathrm{TM}}$ monitoring during deep-sedated ERCP.

Methods: One hundred patients who underwent ERCP in a single year were randomly assigned to either group C or group N. Patients in group C (52) were sedated using the Modified Observer's Assessment of Alertness/Sedation (MOAA/S) scale. Patients in group N (48) were sedated using the Narcotrend ${ }^{\mathrm{TM}}$ system. The MOAA/S scale 1 or 2 and the Narcotrend ${ }^{\mathrm{TM}}$ index 47-56 to 57-64 were maintained during the procedure. The primary outcome variable of the study was the successful completion of the endoscopic procedure. The secondary outcome variables were the total dose of propofol used during the procedure, complications during and immediately after procedure, and recovery time.

Results: All endoscopies were completed successfully. The mean total dose of propofol in group $\mathrm{C}$ was significantly lower than that in group N. However, the mean dose of propofol, expressed as dose $/ \mathrm{kg}$ or dose $/ \mathrm{kg} / \mathrm{h}$ in both groups, was not significantly different $(P=0.497,0.136)$. Recovery time, patient tolerance and satisfaction, and endoscopist satisfaction were comparable between the two groups. All sedation-related adverse events during and immediately after the procedure, such as hypotension, hypertension, tachycardia, bradycardia, transient hypoxia, and upper airway obstruction, in group $\mathrm{C}(62.2 \%)$ were significantly higher than in group $\mathrm{N}$ (37.5\%) $(P=0.028)$.

Conclusion: Clinical assessment and Narcotrend ${ }^{\mathrm{TM}}$-guided sedation using propofol for deep sedation demonstrated comparable propofol dose and recovery time. Both monitoring systems were equally safe and effective. However, the Narcotrend ${ }^{\mathrm{TM}}$-guided sedation showed lower hemodynamic changes and fewer complications compared with the clinical assessment-guided sedation.

Keywords: deep sedation, endoscopic retrograde cholangiopancreatography, clinical assessment, Narcotrend ${ }^{\mathrm{TM}}$ monitoring

\section{Introduction}

There is a growing interest in using propofol for sedation in endoscopic procedures. ${ }^{1-4}$ Propofol is commonly used as an anesthetic agent in endoscopic retrograde cholangiopancreatography (ERCP). It is a fast-acting drug with a short half-life that results in rapid recovery. It also has a favorable pharmacokinetic profile suitable for the induction and maintenance of intravenous anesthesia. However, it has a narrow therapeutic window and has cardiorespiratory depressant effects. Currently, administration of 
propofol is guided by monitoring clinical signs and hemodynamic data. Many previous studies have reported that a slower rate of propofol administration for anesthesia results in smaller dose requirements. ${ }^{5,6}$ Hypotension seen during induction is observed to be attenuated by the use of titrated propofol. ${ }^{7}$ However, level of consciousness cannot be reliably judged by somatic or hemodynamic response alone.

Because depth of sedation cannot be reliably judged by clinical assessments alone, a reliable method is needed to measure the hypnotic component of sedation and anesthesia. Recently, processed electroencephalography (EEG) variables such as the spectral edge frequency, bispectral index (BIS), and Narcotrend ${ }^{\mathrm{TM}}$ (Monitor Technik, Hannover Medical School, Germany) were developed to ease EEG interpretation. These tools have been reported to be more precise in the measurement of sedation level. ${ }^{8-10}$

The Narcotrend ${ }^{\mathrm{TM}}$ performs a computerized analysis of the raw EEG. The Narcotrend ${ }^{\mathrm{TM}}$ has two recording modes: the one-channel mode as the standard for the assessment of the depth of hypnosis during anesthesia and sedation, and the two-channel mode for comparison of signals from the two hemispheres of the brain. After accounting for artifact, a multivariate statistical algorithm is used for analysis, which results in a six-stage classification from A (awake) to $\mathrm{F}$ (general anesthesia/coma) and 14 substages. ${ }^{11}$ In the current version, the Narcotrend ${ }^{\mathrm{TM}}$ EEG classification has 15 substages, as described in Table 1.

In our previous study, we showed that dose requirement and sedation-related complications using diluted propofol for sedation in patients undergoing ERCP were significantly less than when using undiluted propofol.

Table I Narcotrend ${ }^{\mathrm{TM}}$ stages and the respective Narcotrend ${ }^{\mathrm{TM}}$ index ranges (software version 4.0)

\begin{tabular}{lll}
\hline & \multicolumn{2}{l}{ Narcotrend ${ }^{\text {TM }}$} \\
\cline { 2 - 3 } Stage & Index \\
\hline Awake & A & $95-100$ \\
Sedated & B0 & $90-94$ \\
& BI & $85-89$ \\
Light anesthesia & B2 & $80-84$ \\
& C0 & $75-79$ \\
General anesthesia & CI & $70-74$ \\
& C2 & $65-69$ \\
General anesthesia with & D0 & $57-64$ \\
deep hypnosis & DI & $47-56$ \\
General anesthesia with & D2 & $37-46$ \\
increasing burst suppression & E0 & $27-36$ \\
\hline
\end{tabular}

However, patients in that study were sedated using only clinical assessment. ${ }^{6}$ Therefore, our aim of this study was to determine and compare the clinical efficacy of propofol deep sedation using either clinical assessment or the Narcotrend $^{\mathrm{TM}}$ index as a guide for depth of sedation in patients undergoing ERCP.

\section{Methods}

\section{Subjects}

A total of 176 consecutive patients from a tertiary care teaching hospital, Siriraj Hospital, Bangkok, Thailand, were eligible for the study. These patients were at least 18 years of age and underwent ERCP procedures. Exclusion criteria included any clinical evidence of severe liver disease, and patients who had American Society of Anesthesiologists (ASA) physical status IV or V. This present study was approved by the Institutional Review Board of the Faculty of Medicine Siriraj Hospital. All the enrolled patients provided written informed consent to undergo the procedures and to participate in the study.

\section{Study design}

This study was a randomized controlled study. The primary outcome variable of the study was the successful completion of the endoscopic procedure. The secondary outcome variables were the total dose of propofol used during the procedure, recovery time, patient tolerance and satisfaction, endoscopist satisfaction, and complications during and immediately after procedure. The amount of propofol used was compared as total dose, dose $/ \mathrm{kg}$, or dose $/ \mathrm{kg} / \mathrm{h}$. Recovery time was defined as the time after the end of procedure to patient awakening.

All patients were randomized into two groups using sealed envelopes. In group C, 52 patients were sedated using clinical assessment with depth of sedation assessed with the use of the Modified Observer's Assessment of Alertness/ Sedation (MOAA/S) scale. ${ }^{12}$ In group N, 48 sedated patients were sedated using the Narcotrend ${ }^{\mathrm{TM}}$ system. The anesthetic personnel who sedated the patients relied exclusively on the Narcotrend ${ }^{\mathrm{TM}}$ index in determining the propofol dose given to the patients. However, patient observation might have played a role in the decision making if the patient was clinically sedated inadequately. However, all patients in both groups were monitored with the Narcotrend ${ }^{\mathrm{TM}}$ system, but the patients in group $\mathrm{C}$ were not sedated using the Narcotrend ${ }^{\mathrm{TM}}$. Additionally, the anesthetic personnel who sedated the patients in group $\mathrm{C}$ did not see the Narcotrend ${ }^{\mathrm{TM}}$ index. Electrode positions for EEG monitoring were the two channel recordings. 


\section{ERCP procedure}

The procedure was carried out using an Olympus video duodenoscope (TJF 160 R, Olympus Corporation, Tokyo, Japan). The endoscopists were three staff endoscopists, who had more than 10 years of ERCP experience. The procedure was performed with the patient either in a prone or left lateral position. Successful completion of the endoscopic procedure was defined as completion of the procedure as intended once the procedure had started, and completion of the procedure without changing anesthetic technique.

\section{Sedation procedure}

All sedation was carried out by the anesthetic personnel, who were anesthetic nurses and second-year residents in the anesthesiology residency program, directly supervised by a staff anesthesiologist in the endoscopy room. The anesthetic personnel who sedated the patients were the same in both groups. Each patient was monitored for blood pressure, heart rate, EEG, and oxygen saturation $\left(\mathrm{SpO}_{2}\right)$. No premedications were administered before the procedure. All patients received supplemental oxygenation via nasal canula.

The patients were sedated with $0.03 \mathrm{mg} / \mathrm{kg}$ of midazolam and $1 \mathrm{mcg} / \mathrm{kg}$ of fentanyl as well as propofol titrated according to the randomization procedure. All sedations were deep sedation, in accordance with guidelines of the ASA. ${ }^{13}$ In group C, propofol was clinically titrated at 5 -minute intervals using the MOAA/S scale to assess depth of sedation. In group $\mathrm{N}$, propofol was titrated continuously using the Narcotrend ${ }^{\mathrm{TM}}$ system. Propofol was given intravenously by continuous infusion with a syringe pump in all patients. Five minutes before the end of the procedure, continuous intravenous infusion of propofol was stopped. Crystalloid solution was used for maintenance fluid in all cases. The total amounts of intravenous fluid including crystalloid solution and normal saline used in both groups were comparable.

\section{Sedation level assessment}

The MOAA/S scale was used for clinical assessment of the depth of sedation in group $\mathrm{C}$. The MOAA/S score ranges from 1 to 5 ( 1 = unresponsive to shaking, $2=$ responsive to shaking only, 3 = responsive to loud verbal command, $4=$ lethargic but responsive to normal verbal command, and $5=$ responsive and alert). In group $\mathrm{C}$, the sedation level was targeted and maintained at scale 1 or 2 . The Narcotrend ${ }^{\mathrm{TM}}$ system classification of depth of sedation is shown in Table $1 .{ }^{14}$ In group N, sedation was maintained with the Narcotrend ${ }^{\mathrm{TM}}$ system at index $47-56$ to $57-64$. If the depth of sedation was too light, a bolus dose of propofol
(10-20 mg) was administered until the target MOAA/S scale or the Narcotrend ${ }^{\mathrm{TM}}$ stage was reached. Additionally, if the patient was sedated too deeply, an intravenous infusion of propofol was held.

\section{Propofol requirement and complication}

Propofol used, including mean total dose, dose $/ \mathrm{kg}$, and dose $/ \mathrm{kg} / \mathrm{h}$, was compared between the two groups. In addition, the recovery time of these two groups was also evaluated. The complications during and immediately after the ERCP were recorded as follows: hypotension (decrease by $20 \%$ from baseline), hypertension (increase by $20 \%$ from baseline), bradycardia (decrease in heart rate by $20 \%$ from baseline), tachycardia (increase in heart rate by $20 \%$ from baseline), $\mathrm{SpO}_{2}(<90 \%)$, and upper airway obstruction.

\section{Analysis}

Results were expressed as mean \pm standard deviation (SD) or percentage (\%) when appropriate. Comparisons between clinical assessment and Narcotrend ${ }^{\mathrm{TM}}$ system monitoring groups were compared using Chi-square tests (for categorical variables), Chi-square tests for trend (for ordinal variables), and two-sample independent $t$-tests (for continuous variables). The statistical software package SPSS for Window Version 11 (SPSS Inc., Chicago, IL, USA) was used to analyze the data. All statistical comparisons were made at the two-sided 5\% level of significance.

\section{Results}

Table 2 summarizes the clinical characteristics of all the patients ( 52 patients in group $\mathrm{C}$; 48 patients in group $\mathrm{N}$ ). The mean ages in groups $\mathrm{C}$ and $\mathrm{N}$ were 58.1 (14.9) years and 60.1 (13.8) years, respectively. Patients in both groups were similar with respect to patient age, sex, weight, height, ASA physical status, preprocedure volume status, presedation problems, duration of procedure, and indications for ERCP.

Table 3 shows the success rate, mean dose of propofol, recovery time, patient tolerance and satisfaction, and endoscopist satisfaction in the two groups. All endoscopic procedures in both groups were completed successfully using the deep sedation technique. The total propofol dose in group $\mathrm{C}$ was significantly lower than in group $\mathrm{N}$ $(P=0.037)$. However, the mean dose $/ \mathrm{kg}$ and $\mathrm{dose} / \mathrm{kg} / \mathrm{h}$ of propofol in both groups was not statistically significantly different $(P=0.497$ and 0.136$)$. The mean recovery time in the clinical assessment group was relatively shorter than in the Narcotrend ${ }^{\mathrm{TM}}$ group $(P=0.241)$. Patient tolerance and satisfaction as well as endoscopist satisfaction in both groups 
Table 2 Characteristics of patients, duration, and indications of procedure (mean, standard deviation [SD], and percentage)

\begin{tabular}{|c|c|c|c|}
\hline & $\begin{array}{l}\text { Group } C^{a} \\
(n=52)\end{array}$ & $\begin{array}{l}\text { Group } N^{b} \\
(n=48)\end{array}$ & $P$ value \\
\hline Age (years) (mean, SD) & $58.1(14.9)$ & $60.1(13.8)$ & 0.369 \\
\hline \multicolumn{4}{|l|}{ Gender (\%) } \\
\hline Male & $23(44.2)$ & $22(45.8)$ & 0.872 \\
\hline Female & $29(55.8)$ & $26(54.2)$ & \\
\hline Weight (kg) (mean, SD) & $54.8(10.6)$ & $54.5(9.8)$ & 0.543 \\
\hline Height $(\mathrm{cm})($ mean, SD) & $159.5(7.3)$ & $156.9(9.3)$ & 0.315 \\
\hline \multicolumn{4}{|c|}{ American Society of Anesthesiologists physical status (\%) } \\
\hline I & $14(26.9)$ & $8(16.7)$ & 0.320 \\
\hline II & $29(55.8)$ & $27(56.2)$ & \\
\hline III & $9(17.3)$ & $13(27.1)$ & \\
\hline \multicolumn{3}{|c|}{ Preprocedure volume status } & 0.060 \\
\hline Normal & $45(86.5)$ & $37(77.1)$ & \\
\hline Mild hypovolemia & $6(11.5)$ & II (22.9) & \\
\hline Moderate hypovolemia & $\mathrm{I}(\mathrm{I} .9)$ & 0 & \\
\hline $\begin{array}{l}\text { Duration of sedation }(\mathrm{min}) \\
\text { (mean, SD) }\end{array}$ & $35.9(15.1)$ & $35.9(15.8)$ & 0.185 \\
\hline Indication & & & 0.989 \\
\hline Choledocholithiasis & $22(42.3)$ & $20(4 \mid .7)$ & \\
\hline \multicolumn{4}{|l|}{ Biliary stricture } \\
\hline Malignancy & $18(34.6)$ & $18(37.5)$ & \\
\hline Benign & $5(9.6)$ & $4(8.3)$ & \\
\hline Others & $7(13.5)$ & $6(12.5)$ & \\
\hline
\end{tabular}

Notes: a ${ }^{G}$ roup C: clinical assessment; ${ }^{\mathrm{b}} \mathrm{Group} \mathrm{N}$ : Narcotrend ${ }^{\mathrm{TM}}$ monitoring.

were not statistically significantly different $(P=0.951,0.993$, and 0.871 , respectively).

Hemodynamic parameters, including systolic and diastolic blood pressure, heart rate, and $\mathrm{SpO}_{2}$, are shown in Table 4 . Mean systolic blood pressure throughout the study was not statistically different between the two groups except at scope insertion and 5 minutes after the scope insertion. Additionally, mean diastolic blood pressure was not statistically different between the two groups except at scope insertion and 5, 10, and 15 minutes after scope insertion. Furthermore, there were significant differences in heart rate at scope insertion and 5 and 20 minutes after scope insertion. $\mathrm{Mean} \mathrm{SpO}_{2}$ of all patients was $99 \%$ throughout the procedure.

Overall sedation-related adverse events during and immediately after ERCP in the clinical assessment group were significantly higher than in the Narcotrend ${ }^{\mathrm{TM}}$ monitoring group $(P=0.028)$. Moreover, cardiovascular and respiratory system-related adverse events in group $\mathrm{C}$ were relatively greater than those in group $\mathrm{N}(P=0.275$ and 0.062). Hypotension was the most common adverse event in both groups. However, more hypotension was observed in group C compared with group $\mathrm{N}(P=0.327$, Table 5). All complications were minor and easily treated without sequelae.
Table 3 Success rate (n, \%), mean dose of propofol, recovery time (mean, standard deviation, range), patient tolerance and satisfaction, and endoscopist satisfaction (n, \%)

\begin{tabular}{|c|c|c|c|}
\hline & $\begin{array}{l}\text { Group Ca } \\
(n=52)\end{array}$ & $\begin{array}{l}\text { Group } N^{b} \\
(n=48)\end{array}$ & $P$ value \\
\hline Success rate & $52(100.0)$ & $48(100.0)$ & 1.000 \\
\hline \multicolumn{4}{|l|}{ Mean dose of propofol } \\
\hline Total dose (mg) & $\begin{array}{l}198.7(95.0) \\
30.0-490.0\end{array}$ & $\begin{array}{l}247.3(129.3) \\
60.0-590.0\end{array}$ & $0.037^{*}$ \\
\hline $\begin{array}{l}\text { Dose/body weight } \\
(\mathrm{mg} / \mathrm{kg})\end{array}$ & $\begin{array}{l}3.7(1.8) \\
0.7-9.8\end{array}$ & $\begin{array}{l}4.5(2.1) \\
1.2-9.9\end{array}$ & 0.497 \\
\hline $\begin{array}{l}\text { Dose/body weight } / \text { time } \\
(\mathrm{mg} / \mathrm{kg} / \mathrm{h})\end{array}$ & $\begin{array}{l}6.8(3.8) \\
1.7-18.0\end{array}$ & $\begin{array}{l}7.7(3.0) \\
2.8-16.8\end{array}$ & 0.136 \\
\hline Recovery time (min) & $\begin{array}{l}33.2(15.7) \\
10.0-90.0\end{array}$ & $\begin{array}{l}35.9(15.8) \\
10.0-70.0\end{array}$ & $0.24 I$ \\
\hline Patient tolerance & & & 0.951 \\
\hline Exceptional & $25(48.1)$ & $22(45.8)$ & \\
\hline Well & $17(32.7)$ & $18(37.5)$ & \\
\hline Fair & $8(15.4)$ & $6(12.5)$ & \\
\hline Poor & $2(3.8)$ & $2(4.2)$ & \\
\hline Patient satisfaction & & & 0.993 \\
\hline Very satisfied & $27(51.9)$ & $25(52.1)$ & \\
\hline Satisfied & $17(32.7)$ & $16(33.3)$ & \\
\hline Neutral & $8(15.4)$ & $7(14.6)$ & \\
\hline Dissatisfied & 0 & 0 & \\
\hline \multicolumn{2}{|c|}{ Endoscopist satisfaction } & & $0.87 \mathrm{I}$ \\
\hline Very satisfied & $20(38.5)$ & $20(4 \mid .7)$ & \\
\hline Satisfied & $17(32.7)$ & $17(35.4)$ & \\
\hline Neutral & II (2I.I) & $9(18.7)$ & \\
\hline Dissatisfied & $4(7.7)$ & $2(4.2)$ & \\
\hline
\end{tabular}

\section{Discussion}

This present clinical study evaluated the clinical efficacy of propofol for deep sedation in ERCP patients using clinical assessment compared with Narcotrend ${ }^{\mathrm{TM}}$ system monitoring. Our results demonstrated that clinical assessment and Narcotrend ${ }^{\mathrm{TM}}$ system monitoring can be used successfully to provide deep sedation in patients undergoing ERCP without serious adverse events. Narcotrend ${ }^{\mathrm{TM}}$ system monitoring compared with clinical assessment monitoring with the MOAA/S scale did not result in a reduction in drug dose requirements or recovery time. However, hemodynamic alteration in group $\mathrm{C}$ was significantly greater than that in group N. Consequently, the use of the Narcotrend ${ }^{\mathrm{TM}}$ system for monitoring significantly reduced sedation-related adverse events.

EEG-based monitoring was first introduced with BIS monitoring in $1996 .{ }^{15}$ The number shown on the monitor is processed from EEG and has been shown to correlate well with the level of sedation. The Narcotrend ${ }^{\mathrm{TM}}$ system similarly uses EEG-guided monitoring. Previous studies had found a sufficient correlation between Narcotrend ${ }^{\mathrm{TM}}$ and BIS. ${ }^{16-18}$ 
Table 4 Hemodynamic parameters: systolic blood pressure (SBP) and diastolic blood pressure (DBP) (mm Hg), heart rate (HR) (beats/minute), and oxygen saturation $\left(\mathrm{SpO}_{2}, \%\right)$ (mean, standard deviation)

\begin{tabular}{|c|c|c|c|}
\hline & $\begin{array}{l}\text { Group } C^{a} \\
(n=52)\end{array}$ & $\begin{array}{l}\text { Group } N^{b} \\
(n=48)\end{array}$ & $P$ value \\
\hline \multicolumn{4}{|l|}{ Baseline } \\
\hline SBP, DBP & $123.8(17.9,69.7(13.7)$ & I 40.5 (25.3), 73.8 (I 2.4$)$ & $0.098,0.067$ \\
\hline $\mathrm{HR}, \mathrm{SpO}_{2}$ & 77.5 (I2.4), 99.3 (I.0) & 82.3 (I2.2), $99.5(0.9)$ & $0.126,0.196$ \\
\hline \multicolumn{4}{|c|}{ Scope insertion } \\
\hline SBP, DBP & $121.1(17.5), 7 \mid .6(13.0)$ & I 30.2 (24.0), 73.5 (9.4) & $0.013 * 0.046 *$ \\
\hline $\mathrm{HR}, \mathrm{SpO}_{2}$ & 78.5 (I2.5), $99.6(0.8)$ & 81.0 (16.7), 99.5 (1.0) & $0.027, * 0.775$ \\
\hline \multicolumn{4}{|l|}{$5 \mathrm{~min}$} \\
\hline SBP, DBP & I $20.3(20.4), 69.2(13.6)$ & I 28.4 (23.5), 73.7 (I2.9) & $0.011, * 0.019 *$ \\
\hline $\mathrm{HR}, \mathrm{SpO}_{2}$ & 79.9 (10.7), $99.5(0.9)$ & 83.1 (II.0), 99.5 (I.0) & $0.006, * 0.390$ \\
\hline \multicolumn{4}{|l|}{$10 \mathrm{~min}$} \\
\hline SBP, DBP & II8.9 (I7.4), 7I.I (10.9) & II 9.3 (19.9), 70.3 (13.9) & $0.052,0.012 *$ \\
\hline $\mathrm{HR}, \mathrm{SpO}_{2}$ & 78.9 (I0.5), $99.7(0.6)$ & 81.4 (II.I), $99.5(0.8)$ & $0.085,0.670$ \\
\hline \multicolumn{4}{|l|}{$15 \mathrm{~min}$} \\
\hline SBP, DBP & II 7.0 (I5.9), 72.3 (II.I) & II 4.9 (I9.5), 69.3 (II.8) & $0.272,0.008 *$ \\
\hline $\mathrm{HR}, \mathrm{SpO}_{2}$ & 81.5 (9.2), $99.7(0.6)$ & 82.6 (I3.7), 99.4 (0.9) & $0.131,0.232$ \\
\hline \multicolumn{4}{|l|}{$20 \mathrm{~min}$} \\
\hline SBP, DBP & I 22.4 (I8.4), 72.4 (I3.6) & II 6.2 (I7.8), 72.3 (I2.4) & $0.088,0.163$ \\
\hline $\mathrm{HR}, \mathrm{SpO}_{2}$ & $83.0(8.8), 99.7(0.6)$ & 84.53 (I I.6), $99.5(0.8)$ & $0.001, * 0.565$ \\
\hline \multicolumn{4}{|l|}{$25 \mathrm{~min}$} \\
\hline SBP, DBP & I 20.3 (20.2), 72.0 (I2.9) & II 8.4 (20.4), 69.7 (I I.2) & $0.194,0.091$ \\
\hline $\mathrm{HR}, \mathrm{SpO}_{2}$ & $82.0(9.6), 99.7(0.7)$ & 84.6 (I3.0), $99.6(0.7)$ & $0.128,0.737$ \\
\hline \multicolumn{4}{|l|}{$30 \mathrm{~min}$} \\
\hline SBP, DBP & 115.2 (I5.6), 7I.9 (II.3) & II 6.2 (2I.9), 67.5 (12.5) & $0.54 I, 0.202$ \\
\hline $\mathrm{HR}, \mathrm{SpO}_{2}$ & $80.6(10.8), 99.7(0.7)$ & 86.7 (I4.0), $99.5(0.9)$ & $0.089,0.223$ \\
\hline \multicolumn{4}{|l|}{$35 \mathrm{~min}^{2}$} \\
\hline SBP, DBP & II 4.5 (I4.4), 74.4 (I2.2) & II 8.2 (17.9), 69.1 (12.6) & $0.254,0.250$ \\
\hline $\mathrm{HR}, \mathrm{SpO}_{2}$ & 80.3 (7.5), $99.2(3.1)$ & $83.0(9.7), 99.6(0.8)$ & $0.093,0.150$ \\
\hline \multicolumn{4}{|l|}{$40 \mathrm{~min}$} \\
\hline SBP, DBP & II4.I (9.9), 7 I.I (I0.0) & I 20.5 (23.I), 72.2 (I5.2) & $0.188,0.161$ \\
\hline $\mathrm{HR}, \mathrm{SpO}_{2}$ & 81.5 (7.1), $99.9(0.3)$ & 86.7 (10.2), $99.6(0.7)$ & $0.200,0.233$ \\
\hline \multicolumn{4}{|l|}{$45 \mathrm{~min}$} \\
\hline SBP, DBP & I I 9.5 (9.0), 75.5 (8.9) & II 5.9 (I4.I), 72.1 (I0.9) & $0.582,0.435$ \\
\hline $\mathrm{HR}, \mathrm{SpO}_{2}$ & $83.3(3.8), 99.8(0.4)$ & $84.8(8.6), 99.9(0.4)$ & $0.248,0.867$ \\
\hline \multicolumn{4}{|l|}{$50 \mathrm{~min}$} \\
\hline SBP, DBP & II 7.3 (5.9), 73.1 (9.4) & II 2.4 (I7.4), 72.9 (I2.0) & $0.44 \mathrm{I}, 0.207$ \\
\hline $\mathrm{HR}, \mathrm{SpO}_{2}$ & 98.3 (34.5), $99.9(0.4)$ & 84.4 (I0.I), $99.5(0.5)$ & $0.255,0.171$ \\
\hline \multicolumn{4}{|l|}{$55 \mathrm{~min}$} \\
\hline SBP, DBP & I I 6.3 (4.7), $77.0(5.7)$ & 109.5 (13.5), $68.7(10.1)$ & $0.199,0.292$ \\
\hline $\mathrm{HR}, \mathrm{SpO}_{2}$ & $80.7(4.2), 100.0(0.0)$ & 86.0 (I I.5), 99.5 (0.5) & $0.372,0.049 *$ \\
\hline \multicolumn{4}{|l|}{$60 \mathrm{~min}$} \\
\hline SBP, DBP & I23.8 (4.4), $80.8(2.6)$ & $104.3(14.6), 68.0(14.7)$ & $0.109,0.390$ \\
\hline $\mathrm{HR}, \mathrm{SpO}_{2}$ & $82.4(4.3), 100(0.0)$ & $85.0(8.3), 99.5(1.0)$ & $0.174,0.236$ \\
\hline
\end{tabular}

Notes: ${ }^{\mathrm{G}} \mathrm{Group} \mathrm{C}$ : clinical assessment; ${ }^{\mathrm{b}} \mathrm{Group} \mathrm{N}$ : Narcotrend ${ }^{\mathrm{TM}}$ monitoring; *Considered to be of statistical significance.

The correlation between the Narcotrend ${ }^{\mathrm{TM}}$ stages and the respective Narcotrend ${ }^{\mathrm{TM}}$ index ranges was described by Kreuer et $a 1,{ }^{16}$ as shown in Table 1 .

Moderate or deep sedation is often used for patients undergoing ERCP. In current practice, all sedation for ERCP procedures is carried out using propofol by the anesthesiology team. ${ }^{19}$ Clinical assessment alone has been the guide for depth of sedation in titrating propofol dose. In our practice, EEG-guided monitoring devices are not used.
Serious complications with propofol-based sedation, especially respiratory and cardiovascular adverse events, can occur. Although rare, these complications need to be recognized rapidly and appropriately managed to avoid the risk of brain damage, cardiac arrest, or death. Given its narrow therapeutic window and short half-life, propofol needs to be carefully titrated to effect. Careful monitoring of depth of sedation is therefore important. In previous studies, there were large variations in the dosages of propofol given for sedation during 
Table 5 Sedation-related adverse events during and immediately after endoscopic retrograde cholangiopancreatography (n, \%)

\begin{tabular}{|c|c|c|c|}
\hline & $\begin{array}{l}\text { Group Ca } \\
(n=52)\end{array}$ & $\begin{array}{l}\text { Group } N^{b} \\
(n=48)\end{array}$ & $P$ value \\
\hline Overall & $32(61.5)$ & $19(39.6)$ & $0.028 *$ \\
\hline Cardiovascular & $24(46.2)$ & $17(35.4)$ & 0.275 \\
\hline Hypotension & $20(38.5)$ & $14(29.2)$ & 0.327 \\
\hline Hypertension & I (I.9) & 0 & 0.334 \\
\hline Bradycardia & $2(3.8)$ & $\mathrm{I}(2.1)$ & 0.606 \\
\hline Tachycardia & 0 & $2(4.2)$ & 0.137 \\
\hline Arrhythmia & I (I.9) & 0 & 0.334 \\
\hline Respiratory & $8(15.4)$ & $2(4.2)$ & 0.062 \\
\hline Hypoxia (oxygen saturation <95\%) & $4(7.7)$ & $\mathrm{I}(2.1)$ & 0.199 \\
\hline Upper airway obstruction & $4(7.7)$ & $\mathrm{I}(2 . \mathrm{I})$ & 0.199 \\
\hline
\end{tabular}

Notes: a Group C: clinical assessment; ' ${ }^{\mathrm{G}}$ Group N: Narcotrend ${ }^{\mathrm{TM}}$ monitoring; ${ }^{*}$ Considered to be of statistical significance.

endoscopic procedures..$^{2-4}$ Consequently, there was a great individual variability in drug levels needed to achieve certain desired effects. There is no absolute correlation between administered doses of sedatives and the level of responsiveness.

Traditional methods of assessing the level of sedation have relied primarily on subjective assessment of the patient and alteration in vital signs. However, the value of hemodynamics to assess depth of anesthesia remains controversial. ${ }^{20}$ Mean arterial pressure can be only an indirect parameter to estimate hypnotic effects. Changes in arterial blood pressure are mediated by cardiodepressive side effects of sedative agents. Blood pressure was therefore far more likely to predict increasing and decreasing doses of sedative agents rather than any particular stages of depth of sedation.

The OAA/S scale relies on speech and facial expression, which are often difficult to assess in patients undergoing ERCP. ${ }^{12}$ The disadvantage of this scale is that repeated verbal or tactile stimulation of the patient is required to elicit a response.

Given these limitations, monitors that could objectively assess the level of sedation would be extremely useful. EEG-based monitoring of the level of consciousness, like BIS or Narcotrend ${ }^{\mathrm{TM}}$, has added to the armamentarium of tools for monitoring patients undergoing moderate to deep sedation. At present, EEG-guided sedation is being used by anesthesiologists to achieve exact titration of hypnotic agents. ${ }^{16,21,22}$ These monitoring devices could potentially be cost saving, in that they could potentially reduce the dose of sedative agents used and allow rapid recovery time. In the review of literature comparing the OAA/S scale with EEGbased monitoring, there is good correlation of the respective scores with depth of sedation. ${ }^{23-26}$ The correlation was also demonstrated by Bower et $\mathrm{a}^{25}$ between the OAA/S scale and BIS monitoring in patients who underwent gastrointestinal endoscopic procedures under conscious sedation.
The impact of EEG-based monitoring in total intravenous anesthesia has been studied. Narcotrend ${ }^{\mathrm{TM}}$ or BIS monitoring in patients undergoing procedures with total intravenous propofol-based anesthesia led to lower propofol consumption, quicker emergence from anesthesia, earlier extubation, and shorter recovery time. ${ }^{17,26,27}$ However, there are no prior data on the impact of EEG-based monitoring in patients undergoing moderate to deep sedation. Our study attempts to assess the impact of Narcotrend ${ }^{\mathrm{TM}}$ monitoring compared with the MOAA/S scale in patients undergoing ERCP with deep sedation with propofol. The findings show that Narcotrend ${ }^{\mathrm{TM}}$ guided sedation during ERCP does not translate to objective advantages over MOAA/S-guided sedation in terms of success rate, propofol consumption, and recovery time. However, the use of Narcotrend ${ }^{\mathrm{TM}}$ monitoring is associated with a reduction of hemodynamic changes and sedation-related complications. These complications, mainly hypotension and upper airway obstruction, were mild and readily treated.

The lack of observance of a reduction in success rate, propofol consumption, and recovery time in our study may be due to the induction regimen. Even though all patients were sedated with propofol, they were all given an induction regimen with fentanyl and midazolam based on their weight. It is possible that this induction regimen may have equalized the need for propofol between the groups and masked the true impact of EEG-based monitoring on propofol consumption. It is logical that because there was no difference in the propofol consumption, the study also did not find a difference in the recovery time. Again, the recovery time may have also been impacted by the administration of fentanyl and midazolam.

There are several limitations to our study. Prior to the administration of propofol, an induction regimen consisting of fentanyl and midazolam was given to all patients. This may have affected the success rate, amount of propofol used, recovery time, and perhaps adverse events. 
However, the mean dose of the induction agents in both groups is comparable. The difference in propofol requirement between the two groups can be directly compared.

\section{Conclusion}

The use of Narcotrend ${ }^{\mathrm{TM}}$ system monitoring compared with clinical monitoring with the MOAA/S scale in patients undergoing deep sedation with propofol for ERCP helped to reduce sedation-related complications but did not increase the success rate, lower propofol consumption, or shorten the recovery time.

\section{Disclaimers}

Ethical approval for this research project was obtained from the Faculty of Medicine, Siriraj Hospital Institutional Review Board.

\section{Disclosure}

The authors report no conflicts of interest in this work.

\section{References}

1. Krugliak P, Ziff B, Rusabrove Y, et al. Propofol vs midazolam for conscious sedation guided by processed EEG during endoscopic retrograde cholangiopancreatography: a prospective, randomized double-blind study. Endoscopy. 2000;32:677-682.

2. Amornyotin S, Aanpreung P, Prakanrattana U, et al. Experience of intravenous sedation for pediatric gastrointestinal endoscopy in a large tertiary referral center in a developing country. Pediatr Anesth. 2009;19: 784-791.

3. Amornyotin S, Chalayonnavin W, Kongphlay S. Propofol-based sedation does not increase rate of complication during percutaneous endoscopic gastrostomy procedure. Gastroenterol Res Prac. 2011. Epub August 3, 2010.

4. Koshy G, Nair S, Norkus EP, et al. Propofol vs midazolam and meperidine for consicious sedation in GI endoscopy. Am J Gastroenteral. 2000;95:1476-1479.

5. Stokes DN, Hutton P. Rate-dependent induction phenomena with propofol: implications for the relative potency of intravenous anesthetics. Anesth Analg. 1991;72:578-583.

6. Amornyotin S, Suraseranivongse S, Muangman S, et al. Comparison of dose requirement of diluted and undiluted propofol for patients undergoing ERCP [In Thai]. Thai J Anesth. 2003;29:6-12.

7. Peacock JE, Lowis RP, Reilly CS, et al. Effect of different rates of infusion for induction of anesthesia in elderly patients. Br J Anaesth. 1990;65:346-352.

8. Kazama T, Ikeda K, Morita K, et al. Investigation of effective anesthesia induction doses using a wide range of infusion rates with undiluted and diluted propofol. Anesthesiology. 2000;92:1017-1028.

9. Kreuer S, Wilhelm W, Grundmann U, et al. Narcotrend index versus bispectral index as electroencephalogram measures of anesthetic drug effect during propofol anesthesia. Anesth Analg. 2004;98:692-697.
10. Schmidt GN, Bischoff P, Standl T, et al. Comparative evaluation of Narcotrend $^{\mathrm{TM}}$, Bispectral index ${ }^{\mathrm{TM}}$, and classical electroencephalographic variables during induction, maintenance, and emergence of a propofol/ remifentanil anesthesia. Anesth Analg. 2004;98:1346-1353.

11. Kugler J. Clinical and Practical Electroencephalography [In German]. Stuttgart: Thieme; 1981.

12. Cohen LB, DeLegge MH, Aisenberg J, et al. AGA Institute review of endoscopic sedation. Gastroenterology. 2007;133:675-701.

13. American Society of Anesthesiologists. Practice guidelines for sedation and analgesia by nonanesthesiologists. An update report by the ASA Task Force on Sedation and Analgesia by Nonanesthesiologists. Anesthesiology. 2002;96:1004-1017.

14. Chisholm CJ, Zurica J, Mironov D, et al. Comparison of electrophysiologic monitors with clinical assessment of level of sedation. Mayo Clin Proc. 2006;81:46-52.

15. Smith MD, Dutton RC, Smith NT. Measuring the performance of anesthetic depth indicators. Anesthesiology. 1996;84:38-51.

16. Kreuer S, Bruhn J, Larsen R, et al. Comparability of Narcotrend ${ }^{\mathrm{TM}}$ index and bispectral index during propofol anaesthesia. Br J Anaesth. 2004;93:235-240.

17. Kreuer S, Biedler A, Larsen R, et al. Narcotrend monitoring allows faster emergence and a reduction of drug consumption in propofolremifentanil anesthesia. Anesthesiology. 2003;99:34-41.

18. Kreuer S, Biedler A, Larsen R, et al. The Narcotrend ${ }^{\mathrm{TM}}$ - a new EEG monitor designed to measure the depth of anaesthesia: a comparison with bispectral index monitoring during propofol-remifentanil-anaesthesia. Anaesthesist. 2001;50:921-925.

19. Amornyotin S, Na-pomphet S, Wongwathanyoo T, Chalayonnavin V. Anesthesia for endoscopic retrograde cholangio-pancreatography (ERCP) from 1999-2003 in Siriraj Hospital: a retrospective study. J Med Assoc Thai. 2004;87:1491-1495.

20. Struys MM, Jensen EW, Smith W, et al. Performance of the ARXderived auditory evoked potential index as an indicator of anesthetic depth: a comparison with bispectral index and hemodynamic measures during propofol administration. Anesthesiology. 2002;96:803-816.

21. Heier T, Steen PA. Assessment of anesthesia depth. Acta Anaesthesiol Scand. 1996;40:1087-1100.

22. Mahon P, Kowalski RG, Fitzgerald AP, et al. Spectral entropy as a monitor of depth of propofol induced sedation. J Clin Monit Comput. 2008;22:87-93.

23. Weaver CS, Hauter WH, Duncan CE, et al. An assessment of the association of bispectral index with 2 clinical sedation scales for monitoring depth of procedural sedation. Am J Emerg Med. 2007;25:918-924.

24. Bauerle K, Greim CA, Schroth M, et al. Prediction of depth of sedation and anaesthesia by the Narcotrend ${ }^{\mathrm{TM}}$ EEG monitor. Anaesthesia. 2004;92:841-845.

25. Bower AL, Ripepi A, Dilger J, et al. Bispectral index monitoring of sedation during endoscopy. Gastrointest Endosc. 2000;52:192-196.

26. Wilhelm W, Kreuer S, Larsen R. Narcotrend EEG monitoring during total intravenous anaesthesia in 4,630 patients. Anaesthesist. 2002;51: 980-988.

27. Weber F, Pohl F, Hollnberger H, et al. Impact of the Narcotrend index on propofol consumption and emergence times during total intravenous anaesthesia with propofol and remifentanil in children: a clinical utility study. Eur J Anaesthesiol. 2005; 22:741-747.
Medical Devices: Evidence and Research

\section{Publish your work in this journal}

Medical Devices: Evidence and Research is an international, peerreviewed, open access journal that focuses on the evidence, technology, research, and expert opinion supporting the use and application of medical devices in the diagnosis, treatment and management of clinical conditions and physiological processes. The identification of novel

\section{Dovepress}

devices and optimal use of existing devices which will lead to improved clinical outcomes and more effective patient management and safety is a key feature. The manuscript management system is completely online and includes a quick and fair peer-review system. Visit http://www. dovepress.com/testimonials.php to read real quotes from authors. 